\title{
LUPUS ERITEMATOSO SISTÉMICO SERONEGATIVO
}

Walter Gabriel Santiago Chaves*, Lisbeth Natalia Morales Rodríguez ${ }^{* *}$, Derly Milena Peña Ramírez ${ }^{* *}$, Narda Piedad Chacón Peña***

\section{Resumen}

El lupus eritematoso sistémico es una enfermedad inflamatoria multisistémica de etiología multifactorial. El $\mathbf{9 0 \%}$ de los casos se registra en mujeres, por lo regular en edad fértil, aunque también puede afectar niños, varones y ancianos. Es más frecuente en personas de raza negra. Las manifestaciones clínicas, curso y pronóstico varían y como norma los anticuerpos antinucleares se encuentran positivos en el $99,5 \%$ de los casos activos. El 0,5\% no lo son, denominándose seronegativos. La técnica ideal y estandarizada para su detección es la inmunofluorescencia usando como sustrato células Hep-2. Una dilución 1:160 es diagnóstica de esta enfermedad del colágeno. No existe cura y el objetivo del tratamiento es el control de los síntomas. Los medicamentos más utilizados son corticoides, antipalúdicos e inmunosupresores.

Palabras clave: lupus eritematoso sistémico, autoanticuerpos.

Abreviaturas: LES, lupus eritematoso sistémico; ANAS, anticuerpos antinucleares.

\section{SERONEGATIVE SYSTEMIC LUPUS ERYTHEMATOSUS}

\section{Abstract}

Systemic lupus erithematosus (SLE) is a systemic inflammatory disease of multifactor etiology. Ninety percent $\mathbf{( 9 0 \% )}$ of cases occur in women during their reproductive years but it can also affect children, males and old age people. It is more common in black subjects. Clinical manifestations, course and prognosis vary and positive antinuclear antibodies is a standard in $99.5 \%$ of all active disease cases. Only $0,5 \%$ are not positive and are known as seronegative cases. Immunofluorecent assay on Hep-2 cell substrate is the ideal and standard detection technique. A titer of 1:160 is considered diagnostic of this connective tissue disease. There is no permanent cure for SLE. The goal of treatment is to relieve symptoms. The most commonly used drugs are corticosteroids, antimalarial and immunosupressive medications.

Key words: Systemic lupus erithematosus, autoantibodies.

Fecha recibido: noviembre II de 2009 - Fecha aceptado: enero 25 de 2010

* Médico internista. Coordinador del Servicio de Medicina Interna, Fundación Universitaria de Ciencias de la Salud. Hospital de San José, Bogotá DC, Colombia.
** Residente de segundo año de Medicina Interna, Fundación Universitaria de Ciencias de la Salud. Bogotá DC, Colombia.

*** Residente de tercer año de Medicina Familiar, Fundación Universitaria de Ciencias de la Salud. Bogotá DC, Colombia. 


\section{Introducción}

LES es una enfermedad crónica caracterizada por la presencia de diversos autoanticuerpos que pueden participar en el daño de múltiples tejidos. Aún no se conoce la etiología pero se han identificado tres factores básicos relacionados: los genéticos, dada la mayor concordancia entre gemelos idénticos comparada con heterocigotos, la asociación con antígenos HLA clase II (HLA-DR2 y DR3) y la presentación más frecuente en familiares que en la población general; los ambientales como la luz UV$\mathrm{B}$, la ingestión de alfalfa y compuestos químicos como las hidralazinas y colorantes del cabello; también se ha relacionado con factores hormonales. ${ }^{1}$

El lupus se presenta con mayor frecuencia en mujeres entre los 16 y 55 años. Cerca del $80 \%$ corresponde al grupo en edad fértil, estimándose que una de cada 1.000 mujeres jóvenes se ve afectada por la enfermedad. ${ }^{2}$ Esta relación varía con la edad. ${ }^{3,4}$ Se producen disparidades étnicas por factores ambientales, socioeconómicos/demográficos, psicosociales, genéticos y clínicos. Predomina en estrato socioeconómico bajo. ${ }^{5,6} \mathrm{La}$ incidencia y prevalencia varían a través del mundo, siendo mayores entre la población hispana y afroamericana. El diagnóstico se realiza con base en los criterios corregidos para la clasificación del LES del Colegio Americano de Reumatología (1997). Con el propósito de identificar pacientes en estudios clínicos, se dice que una persona tiene LES si cuatro o más de los once criterios están presentes de manera simultánea o serial durante cualquier período de observación. ${ }^{6,78}$ Los marcadores serológicos son elementos esenciales del diagnóstico, en especial los ANAS que se encuentran positivos en el $99,5 \%$ de los casos activos. ${ }^{8}$

El LES tiene un curso clínico variable con manifestaciones multisistémicas a nivel renal, cutáneo, neurológico y articular que es el más frecuente, además de compromiso hematológico y síntomas constitucionales. ${ }^{1,9,10} \mathrm{Cerca}$ del $85 \%$ tienen compromiso renal que se manifiesta después del primer año del diagnóstico. La Organización Mundial de la Salud (OMS) ha definido una clasificación morfológica de las biopsias renales en el LES, revisada por la Sociedad Internacional de Nefrología $(S I N)$ y la Sociedad de Patología Renal. Las clases histológicas van desde compromiso mesangial mínimo hasta nefritis con esclerosis avanzada. ${ }^{11-14}$ La utilización de cultivos de células humanas Hep-2 se ha constituido como la alternativa más utilizada para la detección de ANAS a nivel mundial. A pesar de la variabilidad de los sustratos para su obtención, ellas han demostrado una buena sensibilidad y especificidad en pacientes con LES. Estas células tumorales se encuentran en proceso de división y contienen abundantes moléculas nucleoproteicas que permiten la detección de una amplia gama de autoanticuerpos. ${ }^{7}$ El resultado se considera negativo cuando no se discrimina un patrón fluorescente definido. Se debe tener en cuenta que la no detección de anticuerpos en la prueba no implica ausencia de enfermedad. Esto puede deberse a la baja concentración de antígenos en el sustrato. ${ }^{15}$ No hay criterios aceptados para el diagnóstico mediante imágenes, aunque la radiología desempeña un papel auxiliar para la detección y manejo de esta enfermedad..$^{16}$ Los índices para medir actividad del LES son el SLEDAI-2000 y el BILAG-2004, que ayudan a optimizar el tratamiento. ${ }^{17}$

La nefritis lúpica suele asociarse con ANAS y antiDNA positivos y puede ser el primer síntoma. En raras ocasiones los marcadores serológicos están ausentes al principio y se tornan positivos después de algún tiempo. Los posibles mecanismos implicados en esta asociación poco frecuente incluyen un exceso de difusión de los antígenos o los bajos niveles de inmunoglobulinas en el plasma asociados con proteinuria masiva. ${ }^{18}$ En el tratamiento del LES sin grandes manifestaciones multisistémicas los antimaláricos y/o glucocorticoides son benéficos; cuando no responden al tratamiento o no están en condiciones para reducir las dosis de esteroides por debajo de lo aceptable para uso crónico, pueden utilizarse agentes inmunosupresores como la azatioprina, micofenolato mofetil y metotrexato. ${ }^{14,18,19,20}$ En nefritis lúpica proliferativa los glucocorticoides en combinación con agentes inmunosupresores son eficaces contra la progresión a enfermedad renal terminal. A largo plazo ha sido demostrada la utilidad de la ciclofosfamida. ${ }^{21,22,23}$ En el corto y mediano plazo, el micofenolato mofetil ha revelado una eficacia similar en comparación con ciclofosfamida en pulsos con un perfil de toxicidad más bajo. Tras la remisión, las recidivas no son infrecuentes y requieren diligente seguimiento. ${ }^{18}$ 


\section{Presentación del caso clínico}

Paciente femenina de 44 años de edad que ingresa al servicio de urgencias por un episodio de hematoquezia, precedida de deposiciones líquidas claras, deterioro de su clase funcional, cefalea intensa, cervicalgia y refería además fotosensibilidad y artralgias ocasionales de larga data. Había antecedentes de anemia crónica, cefalea e infertilidad que requirió tratamiento hormonal. G2P2A0V2. Al examen físico se encontró saturación de oxígeno de $82 \%$ al FIO2 0.21 , palidez mucocutánea, disminución del murmullo vesicular en ambas bases pulmonares, hepatomegalia de dos centímetros por debajo de reborde costal derecho, onda ascítica positiva y edema de miembros inferiores. Los estudios iniciales evidenciaron leucocitos $4.800 / \mathrm{dL}$, hemoglobina $6.8 \mathrm{~g} / \mathrm{dL}$, hematocrito 22.6, volumen corpuscular medio 65.9, hemoglobina corpuscular media 19.4, ADE 13, Plaquetas $450.000 / \mathrm{dL}$, tiempo de protrombina 11.4 (11.3), tiempo parcial de tromboplastina 26.7 (29.1), creatinina $1.10 \mathrm{mg} / \mathrm{dL}$, nitrógeno ureico $40 \mathrm{mg} / \mathrm{dL}$, proteínas totales $4,7 \mathrm{~g} / \mathrm{dL}$, albúmina $2.4 \mathrm{~g} / \mathrm{dL}$ y hormonas tiroideas normales. Ferritina 9.41 (VR 6.25 - 13.7), hierro 15 (VR 37-181) y perfil de hemólosis negativo. Radiografía de tórax: derrame pleural bilateral (Figuras 1 y 2).

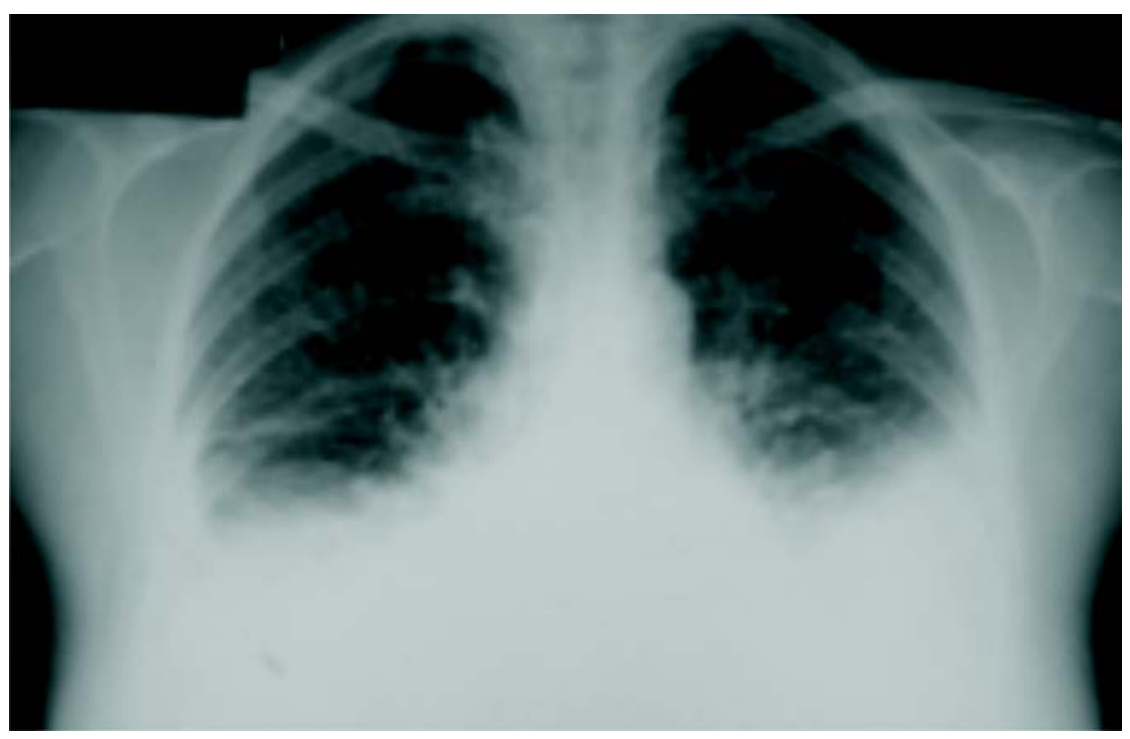

Figura I. Radiografía de tórax con derrame pleural bilateral.

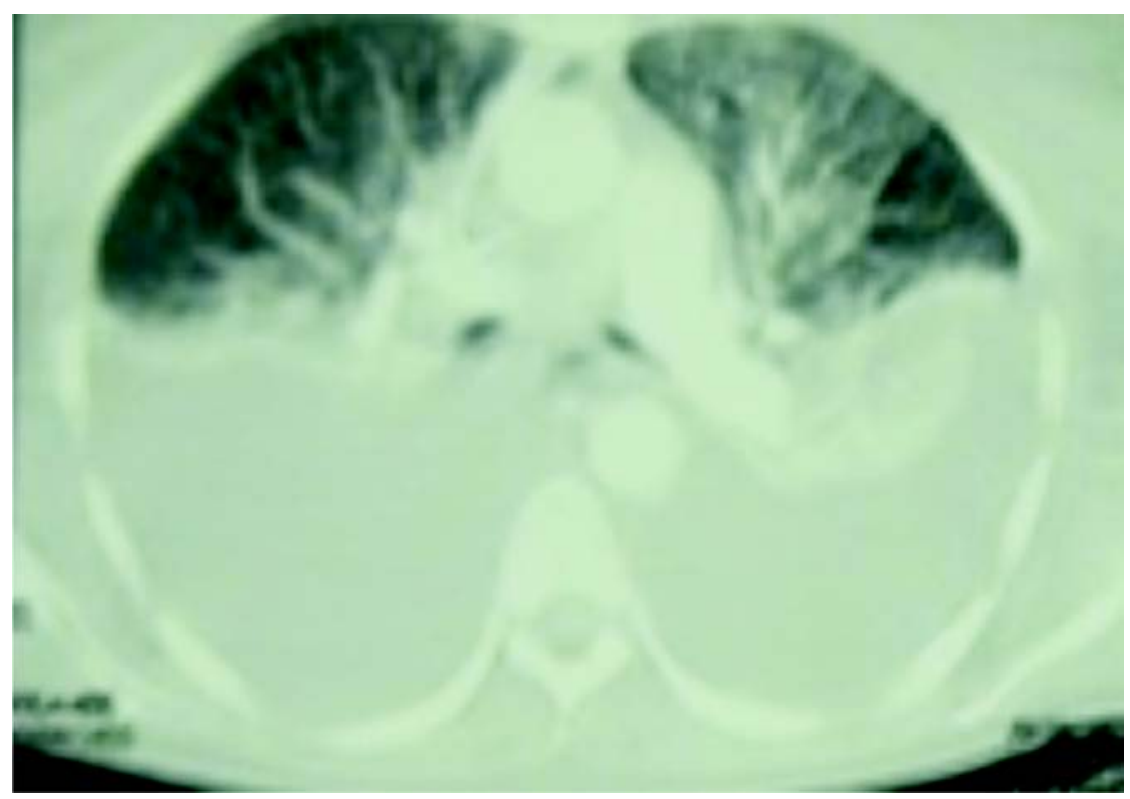

Figura 2. TAC de tórax con derrame pleural bilateral masivo. 
Electrocardiograma normal, estudio de esofagogastroduodenoscopia y colonoscopia normales. Ecocardiograma: pequeño derrame pericárdico de $50 \mathrm{cc}$, ligera esclerosis valvular mitral con mínima regurgitación, hipertensión pulmonar severa (PSAP $70 \mathrm{~mm} \mathrm{Hg}$ ). Toracentesis con derrame pleural izquierdo tipo transudado; C3: 62 (VR 89-187), C4: 8.7 (16.5-40), FRENAS y ANAS negativos. Anticardiolipina G 30 (VR 020), anticoagulante lúpico ausente, Ebstein Barr IGM: 0.57 (0- 0.9), ANAS en inmunofluorescencia indirecta en sustrato Hep-2: no reportan ningún título. Con los hallazgos anteriores el servicio de medicina interna considera los diagnósticos de anemia ferropénica severa, cor anémico, poliserositis, hipertensión pulmonar severa y enfermedad del tejido conectivo versus neoplasia oculta. Durante su evolución la paciente presenta rápido deterioro clínico con dolor torácico y falla ventilatoria aguda. Es trasladada a UCI con sospecha clínica de tromboembolismo pulmonar no demostrado en el angiotac de tórax. Los estudios complementarios muestran crioglobulinas negativas, ANCAS negativo, anti SCL 70 negativo y antiDNA con inmunofluorescencia negativo.

Ante los resultados del perfil inmunológico negativo y el deterioro progresivo de la función renal, se realiza biopsia que reporta glomerulonefritis membranosa tipo 1 secundaria a LES con proliferación mesangial hacia el polo vascular, inmunofluorescencia positiva con $\lg \mathrm{G}$ C3 y Clq, y negativa con $\mathrm{C} 4, \operatorname{lgM}$ e IgA. Evaluando riesgo-beneficio se considera pertinente el inicio de corticoides endovenosos ${ }^{21}$ con adecuada respuesta, tolera protocolo de extubación, disminución franca de la poliserositis y los síntomas. Se anotan como diagnósticos de egreso LES, nefropatía lúpica membranosa, hipertensión pulmonar severa y anemia ferropénica multifactorial. Por evolución satisfactoria es dada de alta con oxígeno domiciliario, corticoides y terapia de rehabilitación integral.

\section{Discusión}

El caso presentado describe a una mujer en edad fértil que consulta por síntomas gastrointestinales, anemia, fotosensibilidad y artralgias crónicas. Se realiza un estudio minucioso con marcadores serológicos pensando en obtener un título anormal de ANAS por inmunofluorescencia o análisis equivalente en cualquier momento ${ }^{24} \mathrm{lle-}$ gando inclusive a repetir los ANAS en diferente sustrato (Hep-2) para evaluar la real presencia de una enfermedad del tejido conectivo. Estos resultados fueron negativos, lo cual obligó a investigar la presencia de otros anticuerpos como antiDNA o bien antiSm, los cuales fueron negativos. Sólo la presencia de un dato positivo débil para anticuerpos anticardiolipina con IgG y leve consumo del complemento eran sugestivos de actividad. ${ }^{5}$ En los diagnósticos diferenciales nunca se descartó la presencia de una neoplasia oculta, por lo cual se estudiaron el tracto gastrointestinal y el aparato ginecológico. El deterioro clínico rápido permitió considerar el tratamiento para una enfermedad autoinmune en el contexto de una paciente joven con enfermedad renal no establecida, poliserositis, anemia multifactorial y fotosensibilidad. El compromiso renal inicial obligaba a descartar nefritis lúpica, por lo cual se realizó la biopsia, valioso elemento clínico que permitió dilucidar la etiología de dichos hallazgos clínicos y paraclínicos, y dio continuidad al tratamiento con corticoides, favoreciendo la recuperación clínica y el restablecimiento de la calidad de vida de la paciente.

Ante la sospecha de una enfermedad autoinmune sistémica se solicita la detección sérica de autoanticuerpos. La metodología más empleada es la inmunofluorescencia indirecta (IFI) que usa como sustrato cortes de tejido, como hígado de ratón o en forma preferencial por su mayor sensibilidad células Hep-2, una línea celular tumoral de origen humano. ${ }^{25,26}$ Se conoce la existencia de un reducido subgrupo de pacientes con LES y con ANAs negativos por IFI que puede estar asociado con manifestaciones clínicas tales como fotosensibilidad, exantema cutáneo, bloqueo cardíaco y en general con una forma más leve de enfermedad sistémica. ${ }^{26}$ Es poco frecuente tener LES y presentar resultado negativo en el análisis de ANA, aunque es posible. En este caso se habla de LES, ANAS negativo. ${ }^{27}$ Dada la alta sensibilidad de los anticuerpos antinucleares para el diagnóstico de LES, la evidencia clínica pone en duda la existencia del lupus seronegativo, excepto que tenga otro anticuerpo que no sea detectado por el sustrato (como en el caso de la paciente) ${ }^{28}$ Hay pocos estudios reportados en la literatura.

El caso nos permite concluir que ante un resultado negativo en los estudios inmunológicos con ANAS y antiDNA 
no podemos descartar LES. También permite dilucidar la importancia de la biopsia renal, ya que es un procedimiento invasivo que permite el análisis detallado del compromiso renal en el contexto de una enfermedad sistémica. ${ }^{29-32}$

\section{Referencias}

1. LES y síndromes relacionados. En: Kelley WN. Tratado de reumatología. Madrid, España: Elsevier; 2006. Vol. 2

2. Cervera R, Khamashta MA, Font J, Sebastiani GD, GilA, Lavilla P, Doménech I. Systemic Lupus Erythematosus: clinical and immunologic patterns of disease expression in a cohort of 1000 patients. Medicine. 1993; 72:113-24.

3. Villalobos R, Rovetto P, Cortés A, Restrepo de Rovetto C. Descripción de casos de nefropatía lúpica diagnosticados por biopsia, en el Hospital Universitario del Valle, Cali, 1995-2000. Colomb Med. 2002: 33(4); 145-48

4. Bustos PG. Pautas y procedimientos en medicina interna. Lupus Eritematoso Sistémico [monografía en Internet]. Buenos Aires: Portales Médicos; 2008[citado 27 Feb. 2010]. Disponible en: http://www.portalesmedicos.com/ publicaciones/articles/915/2/Pautas-y-procedimientos-en-Medicina-Interna.Lupus-eritematoso-sistemico

5. Fundación Mexicana de Lupus. El papel del laboratorio en el diagnóstico y control del lupus [monografía en Internet]. México: La Fundación; 2000[citado 27 Feb. 2010]. Disponible en: http://www.southmex.com.mx/fmxlupus/ www/laboratorio.html

6. Harrison TR. Harrison Principios de medicina interna. México: McGrawHill; 2006

7. Gaviria Jaramillo LM, et al. Características clínicas y serológicas de los pacientes con LES de inicio tardío en una población colombiana. Rev Colomb Reum. 2007: 14(1);23-31

8. Fernandez Met al. A multiethnic, multicenter cohort of patients with systemic lupus erythematosus (SLE) as a model for the study of ethnic disparities in SLE. Arthritis Rheum. 2007 May 15; 57(4):576-84

9. Kim HA, Chung JW, Park HJ. An antinuclear antibody-negative patient with lupus nephritis. Korean J Intern Med. 2009 Mar; 24(1):76-9.

10. Chan TM. Lupus nephritis: induction therapy. Lupus. 2005; 14; s27- 32

11. Weening JJ, D'Agati VD, Schwartz MM, et al. The classification of glomerulonephritis in systemic lupus erythematosus revisited. J Am Soc Nephrol. 2004 Feb;15(2):241-50

12. Carballo OG. Control de la calidad en la determinación de anticuerpos antinucleares por inmunofluorescencia indirecta[monografia en Internet]. Buenos Aires: MANLAB, Hospital Carlos G. Durand. Unidad Inmunología; 2007[citado 27 Feb. 2010]. Disponible en: http://www.emanlab.com.ar/pdf/publicaciones/anticuerpos_anti-nucleares.pdf

13. Waldman M, Appel GB. Update on the treatment of lupus nephritis. Kidney Int. 2006; 70(8): 1403-12.
14. D'Cruz DP, Houssiau FA. The Euro-Lupus Nephritis Trial: the development of the sequential treatment protocol. Lupus 2009; 18(10); 875-7.

15. Tan ME, Cohen SA, Fries FJ, et al. Upadating the American College of Rheumatology Criteria for the Classification of Systemic Lupus Eryhematosus. Arthritis Rheum 1997; 40:1725

16. Benseler SM, Silverman ED. Systemic Lupus Erythematosus. Rheum Dis Clin North Am. 2007 Aug;33(3):471-98.

17. Lalani TA, Kanne JP, Hatfield GA, Chen P. Imaging findings in systemic lupus erythematosus. Radiographics. 2004 Jul-Aug;24(4):1069-86.

18. Contreras $\mathrm{G}$, et al. Sequential therapies for proliferative lupus nephritis. $\mathrm{N}$ Engl J Med. 2004 Mar 4;350(10):971-80.

19. Houssiau FA, Ginzler EM. Current treatment of lupus nephritis. Lupus 2008; 17(5); 426-30.

20. Rahman A, Isenberg DA. Systemic lupus erythematosus. N Engl J Med $2008 \mathrm{Feb} 28 ; 358(9): 929-39$

21. González Naranjo LA, Vásquez Duque GM, et al. Nefropatía lúpica: presentación clínica, clasificación y tratamiento. Rev. Colomb. Reumatol. 2006 Dic.; 13(4): 307-33

22. Flanc RS, Roberts MA, Strippoli GFM, Chadban SJ, Kerr PG, Atkins RC Treatment for lupus nephritis. Cochrane Database Syst Rev. 2004;(1):CD002922. Review

23. Masood S, Jayne D, Karim Y. Beyond immunosuppression - challenges in the clinical management of lupus nephritis. Lupus. $2009 \mathrm{Feb} ; 18(2): 106-15$.

24. Quintana López G, Fernández Aldana A, et al. Aplicación clínica de los anticuerpos en lupus eritematoso sistémico. Rev. Colomb. Reumatol.2003 Mar.; 10(1): 32-45.

25. Spronk PE, Limburg PC, Kallenberg CG. Serological markers of disease activity in systemic lupus erythematosus. Lupus. 1995 Apr; 4(2):86-94

26. Feltkamp TEW. Antinuclear antibody determination in a rutine laboratory. Ann Rheum Dis. 1996 October; 55(10): 723-727.

27. Fuente MC, Bovone NS, Eposto MO. Autoanticuerpos detectados por inmunoensayo lineal en pacientes seronegativos por inmunofluorescencia. Acta bioquím. clín. Latinoam. 2004; 38 (4): 495-8.

28. Bertsias G, Aloannis JP, et al. EULAR recommendations for the management of systemic lupus erythematosus. Ann Rheum Dis. 2008; 67:195-205.

29. Lupus. org [página en Internet]. Washington: Lupus Foundation of America; c2010 [citado 27 Feb. 2010]. Disponible en: http://www.lupus.org/newsite/ index.html

30. Carpio Paniagua Daniel. La biopsia renal: importancia clínica. Cuad. Cir 2003; 17: 112-114

31. Kavanaugh A, Tomar R, Reveille J, Solomon D, Homburger HA. Guidelines for clinical use of the antinuclear antibody test and tests for specific autoantibodies to nuclear antigens. Arch Pathol Lab Med. 2000; 124: 71-81.

32. Sada KE, Makino H. Usefulness of ISN/RPS classification of lupus nephritis J Korean Med Sci. 2009 Jan;24 Suppl:S7-10 